\title{
HETERODOX ORIGIN \\ OF COMICS: CALLIGRAMS, CHRONOLOGIES AND MAPS
}

Andrea Tosti ${ }^{\star}$

\begin{abstract}
The history of the antecedents of the comics has often focused on those expressions (painting, caricature, literature etc.) that presented evident similarities with the medium in question. There are territories that remain little or totally unexplored and that may not only have contributed to give the comics the shape we know today but could still contribute to its constant modernity and launch it towards the challenge of multimedia. The heterodox antecedents chosen here are calligrams, maps and chronologies.
\end{abstract}

Keywords: Comics. Calligrams. Maps.

T he history of modern comics is usually traced back to caricature, through the multiplication of panels, to the creation of the first strips on the pages of newspapers or, in more recent years, to the stories drawn by Töpffer and his successors. This "evolutionary" hypothesis, however, takes into little consideration the cultural mélange from which the comics originate and which includes apparently heterodox elements, compared to those commonly considered as foundations. Elements that have helped define the comics book as a narrative art form outlining some of the most recognizable elements include: the white space, which is both an element that is at the same time cohesive, especially within the page unit, and in the ellipse function among the panels; the ability to make temporal narratives that are not linear but fragmented, parallel and contingent with greater ease than both the pictorial and multi-pictures narratives and, above all, the oral and written narrative; the cooperation of written text and image in order to obtain a concordant narration, with the exception of pantomime or the so-called "mute comics". The list could be long and would include other similar devices (such as rebuses, for 
example, or the diagram, a theme that deserves a separate reflection), but here we decided to focus mainly on calligrams and, in the broadest sense, on visual poetry, on chronologies and, consequently, on maps, with particular attention to chronologies and time maps.

\section{VISUAL POETRY - FROM FIGURED POEMS TO THE INVENTION OF THE WHITE SPACE}

The text composed of word and image - or in which the word becomes image - in calligrams (name taken from the famous anthology of Apollinaire poems of 1918, Calligrammes) or figured poems (from Latin carmina figurata) or still

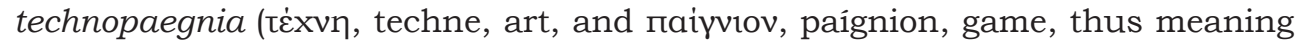
"art game") represents one of the artistic expressions in which the relationship between word and image was more intimate.

Visual poetry can be found across the whole history of writing, first, and then of the book. When we talk about carmina figurata or technopaegnia we speak of written texts, without spacing either between the single letters or between words, which go to form, according to the length of the verses of variable length, geometric shapes (crosses, wineskins etc.). The authors of these compositions obviously aspire to offer an entirety that can be enjoyed before entering into the sequential particularity of reading the written word. The verbal and iconic messages in this type of works are always strictly interdependent, so that one is not understandable without the other or that the absence of one of the two elements blurs the message. Both in its simplest forms - words that reproduce the shape and profile of an object or its silhouette - and in the most complex, such as those of the versus intexti, this very close cohesion can be perceived immediately, even in the absence of specific notions. Form and content are rarely interdependent (as in this case) and the graphic-alphabetic component of the written word becomes predominant over the oral one. Naturally the weight of the visual and verbal systems, in the totality that results in the final work, changes according to the specific cases and, as notes Giovanni Pozzi (1996, p. 25), to the relationship between the two elements, as in every mutual relationship, it can be either majority-minority or balanced.

In short, figurative poetry is expressed as an art form precisely because of the fact that the word, detaching itself from its oral origin, is expressed through the graphic properties of writing.

The image no longer illustrates, in the many senses in which this verb can be understood, an alphabetic text but is delineated, defined and integrated by it, while at the same time containing it. Especially when you consider that the period of greatest blooming of this form (the second half of the SECOND century BC) is during the transition from the papyrus roll to the code, that is, from a unitary text to be unrolled to one composed of various parts and to leaf through - at the moment of the invention of the page, which was going to constitute itself as a new limit, or frame, of the development.

Calligrams are not part of a whole, inserted into a diachronic reading, sheet after sheet, of information, but a unicum to admire, read and decipher. The individual elements - picture, words included in or outlining the image and the verses - can be read at different times and in different ways. However, in what 
is globally called "visual poetry" all these elements cooperate in the construction of the poetic object, which includes them and at the same time it cancels them.

In any case, the compositional complexity of calligrams grows, paving the way for the interweaving of interpretive possibilities and reading paths that shape them as polysemic texts (ORAZI, 1999, p. 147) and virtual bearers of (even) fruitful ambiguities and anticipating in various ways the multi-vector possibilities of comics fruition.

"Reading paths", as Orazi always defines them, to a large extent can be traced back to the figurative $\operatorname{art}^{1}$ (and in other ways sometimes even to abstract art), but their identification is particularly important, especially in approaching certain pages and comics works (this approach can be sometimes ostensibly chaotic) ${ }^{2}$.

After a period of neglect, followed by the seventeenth century during which the genre survived almost exclusively through the comic register, at the beginning of the twentieth century the carmina figurata was rediscovered thanks above all to the surrealist movement, which was especially interested in their visual component. However, a new form of visual poetry ${ }^{3}$ already appeared at the end of the nineteenth century, when the magazine Cosmopolis in May 1897 published Un coup de dés jamais n'abolira le hasard by Mallarmé. In this poetic text, the typographic component plays a new role. Words and phrases are interspersed with white spaces that, replacing the linear sequence of words, become the new tool that the author uses to order the text rhythmically. The gap with respect to the previous poetic tradition, including that of the carmina figurata, is notable and is part of a reflection on the perception and representation of time. In Un Coup de dès, space replaces time: empty and white spaces mark the reading. Mallarmé's is a text "created above all for the eye before the ear" (CAPRONI, 2008, p. 46).

The experiments of visual poetry and calligrammatics conducted between the end of the nineteenth century and the beginning of the twentieth created a further distance from their oldest antecedents. For the first time, the goal is to create a hybrid between poetry and painting. The "programmatic that will merge the arts, poetic and plastic dimensions, which converge in an unprecedented product" finds resonance with the birth and development of the comics, as well as the "imperative of synthesis" (ORAZI, 2011, p. 148), which are typical processes at the root of the twentieth-century calligrammatic art birth.

It is evident that Mallarmé's text ${ }^{4}$ opens new possibilities to visual poetry in the twentieth century and shares a common territory with the comics "with its simultaneous vision of the Page" and its "scoring' of "prismatic subdvisions of the Idea" (MALLARMÉ apud NICHOLLS, 1995, p. 41). On one hand it will allow the development of the research of the most faithful continuator of the tradition

\footnotetext{
They are often paths that derive from the reading direction in each specific culture. In the case of the Western world, from left to right, but which can also be inferred from the texts that inspire a certain work and act as maps to orientate in a tangle of signs which, at first, might seem not narratively ordered.

2 On the experiments aimed at identifying the presence of visual patterns in the reading of comic strips, see Cohn (2013) and Igaki et al. (2004).

3 It would be more accurate to refer to the visual poetry of Mallarmé as at the apex of a path that has seen as other excellent performers other names, among which that of Charles Nodier stands out. In his Histoire du roi de Bohême et de ses sept chateaux, in fact, you can find some examples that refer directly to the work of the French poet, as the phrase "en descendant les sept rampes de l'escalier" composed typographically to postpone, in fact, in the shape of a ladder (NODIER, 2001, p. 107). Moreover, these inventions seem to reverberate, at least in part, even in the graphic work, if not in part already a comic book, by Carl Maria Seyppel and in the stories drawn by Rodolphe Töpffer.

4 Mallarmé knew the form of the comic strip from which he could have borrowed some impressions later merged into his poetic work. The relationship between Mallarmé and the comics has not yet been explored, but the "comic strip" he designed and found by Christophe Wall-Romana (2013, p. 56-57) in the Doucet archive shows that the poet knew and used this form of expression.
} 
of technopaegnia, Apollinaire's works such as Il Pleut, La colombe poignardée et le jet d'eau and other poems included in the collection titled, precisely, Calligrammes, as wel as others, which are also part of the Futurist tradition, such as Lettre-Océan; on the other hand, it will make possible the innovations of Filippo Tommaso Marinetti and of the Futurists, where we see the dissolution of the gutenberghian typographic page. A dissolution carried out through the style of Parole in libertà or Paroliberismo and in which the alphabetic character regains its double sound and visual nature and through which it is freed from the grammatical and syntactical bonds,

[...] but not yet from the centrality of the word. The meaning continues to predominate on the letter. The typographical effects are created for declamatory gesticulation. And they underline and emphasize a sequence that is still entirely verbal. The movement of writing remains progressive and temporal [...]. What Marinetti brings to the tables free words is however a completely necessary outcome of Futurist poetics. Because the great ambition of the Futurists, and the avant-garde in general, is not to renew literature but to get out of literature. To create a new language that crosses the boundaries between the arts, between verbal art and visual art, between writing and noise music ${ }^{5}$ (GUGLIELMI, 2002, p. 263).

An operation, that of "creating a new language that crosses the boundaries between the arts, between verbal art and visual art" (GUGLIELMI, 2002, p. 263) ${ }^{6}$ which will find in comics (think also of the importance of the onomatopoeia in this medium) a privileged vehicle, even if scarcely considered ${ }^{7}$.

The Futurist poetics, as well as that of Mallarmé previously, will open new possibilities to visual poetry, which will find original outlets in concrete poetry and in the various schools linked to the Russian avant-gardes. In the latter case there will be examples of particular interest, but which will actively involve also the first magazines that published comics and cartoons. In this context, the frequent recourse in comics to "words that are not words", that is the onomatopoeias, are words that are expressed mainly through their own graphic component and refer to their phonetic origin.

After all, can the non-pantomime comics also be considered a complex and anomalous form of a calligram? Yes, if we consider the calligram as a visual-verbal conglomerate in which we have a narrative anticipation offered by the whole, embraceable with a single glance, and in which the word enters the perception as a sequential element only at a later time, when reading takes over from watching. And looking and reading have two completely different temporal and spatial approaches.

It is clear to everyone, naturally, how in a narrative art like comics, one of the fundamental elements to consider are time, its use and how it is presented and represented. Through its sequential visual and sequential alphabetic components, the comics develop its own narration. Even in comics, as in Un Coup

5 In this regard, see also the definition of onomalingua by Fortunato Depero and, by way of example, the work Campanelli (Tavola onomalinguistica), 1916, by the same author.

6 In this regard, see also the definition of onomalingua by Fortunato Depero and, by way of example, the work Campanelli (Tavola onomalinguistica), 1916, by the same author.

7 Alfredo Castelli (2006, p. 15) states: "The works of Töppfer have fascinated the writers Mallarmé, Maupassant and De Musset, who have created stories that have remained unpublished", but it was not possible to find other references to support this thesis.

8 The definition, to be understood in a derogatory sense, is of the American psychiatrist Fredric Wertham (1954, p. 144). 
de dés, it, it is (also) the white space between the panels that shapes the flow of time $^{9}$. In the French poet's text, these typographic absences serve to give a new rhythm to versification, at the same time they give a new role to silence, no longer perceived as the absence of word - as in the case of the famous white pages that interrupt the story of Sterne's Tristram Shandy and that the author invites the reader to fill - but as a poetic element in itself. In the comics book, white space is usually a rigid unit, not particularly variable in the sense of space but extensively in the sense of time. Between one panel and the other, a few moments or millennia can pass, or the same spatial unit can be used to divide narratively two contemporary events; indeed, it often underlines its contemporaneity.

If we want to continue this comparison, perhaps a bit clunky but functional, the white space between the panels, which have so much weight in the compositional but also spatial and temporal perception of comics, could have the same function of white space in the text of Mallarmé that has been mentioned, i.e. the function of creating spatial hierarchies, architectures that are organized and unfold in space and even in time. To discuss this we need to talk about maps.

\section{MAPS AND CHRONOLOGIES}

The comics offer a narrative space that can be associated to a map ${ }^{10}$, that is a space aimed at telling a story in which the simultaneity of the coexistence of the elements of the page is offered as a whole to the "reader's" eye before he/she enters the "reading" (sequential or erratic) of the same. Critical literature is moving in this direction, but still not meaningfully ${ }^{11}$. A map of Italy, for example, will first be recognizable by the unmistakable outline of its borders before isolating individual elements such as cities and mountain ranges, in the same way as a comics page.

Before continuing, however, it is necessary to make a further distinction. Maps and chronologies are different things. The maps are simplified representations of a portion of space and can represent real places, places considered to be real or even completely imaginary places. Famous is the maritime map, completely empty, that Carroll inserts in his poem The Hunting of the Snark (1876). Chronologies, on the other hand, are representations of events that take place over time. Of course maps and chronologies can work cooperatively, not only because the latter will often use, to represent the weather, the geographical metaphor, but also because some events (such as human migratory movements) must be represented both in space and time to have a better and fuller understanding.

Naturally, maps, chronologies, genealogical trees and anything else can be physically present inside the comics book to describe the geography of an invented world, for example.

9 And, in the same way, it introduces silence, as Henry Van Lier pointedly introduces the concept of multicadre (multi-panel), the page is seen as a semantic unit. The white dividing the vignettes, for Van Lier, does not serve to introduce a sequential narration or to build a continuity but, rather, to cancel it, introducing moments of silence in which an intermediate, linking image is not created between a vignette and the other, but rather proceed to the destruction of the vignette just used to allow the enjoyment of the next (VAN LIER, 1988).

10 Perhaps it is no accident that, in an attempt to describe the comic, many authors and critics, including Dylan Horrocks, Thierry Groonsteen, Benoît Peeters and, above all, Scott McCloud use the most varied geographical metaphors. For a list of the geographical metaphors used by McCloud in his critical work, see the discussion of Dylan Horrocks (2001).

11 See for example Van Lier (1988), Peeters (1991), Floch (1997), and Groensteen (2007). Horrocks (2001, p. 6) is the clearest invocation: "Then there are countless new maps we could start drawing for ourselves - exploring the connections between comics and literature, film, photography, graphic design, typography, performance, diagrams, or (for that matter) cartography". See also the interesting articles by Antoni Moore (2009; MOORE et al., 2018). 
However, beside this there are other aspects that most interest us. First of all, the fact that both maps and chronologies, throughout their history, have tried to offer schematizations of time and space that were able to achieve their own representative purpose - and partly also narrative - without the aid of or with a minimal appeal to the word and proposing themselves, through different gradations, as a purely visual media, as we also believe the comics strip is. Then, especially for what concerns chronologies, that of the cartographies of time, as well as being a history of overcoming representation through the medium of the word, is also a history of overcoming the representation of time through the metaphor of the straight line. Even more important is the fact that the comics itself can be seen both as a cartography and as a chronology.

The spatial dimension of the comics, the unicum of the page captured in a single glance, makes it possible to grasp the spatial relationships between the bodies and the objects represented, their coordinates, and precedes the other types of approach, that is the sequential reading of the panels and the sequential alphabetical reading ${ }^{12}$, but it also precedes these processes. In short, can the comics answer the fundamental questions posed by Horrocks (2003):

So what happens when we take that fact and put it at the heart of what we're doing - as writers and as readers? What happens when we focus on geographical narrative - the construction of a place - rather than temporal narrative - the construction of a series of events? When we replace plot with landscape as the central organising element? And when, instead of going on a journey through time, we set out to create and explore a space?

Figure 1 - Frank King, Gasoline Alley, Aug. 24, 1930



12 Of course, an absolute cancellation of time is not possible, because there is always the time necessary for the reader to interface with the work. 
Figure 2 - Frank King, Gasoline Alley, Apr. 22, 1934



To try and answer the previous question, see the two Sunday pages by Gasoline Alley, by Frank King. We are looking at an overall representation that is already sufficient for us to emotionally tune into the narrative space of the comics in question. In particular, by trying to exclude words, the compulsory direction of the sequential reading, intended as the path of the gaze along the usual left-right and low-high directions, will be rather bland and, within certain margins, will be re- or de-constructed by the reader. This impression is strengthened, for example in the marine Sunday strip, by the encroachment of some graphic elements over the edge of the panel. This border acts both as a temporal and a spatial separator, in the case of two moments shown in their contemporaneity as in the case of iconic signs (stars) representing stunning and/or pain in the panels 4 and 6 , which encroach on the upper strip, which would conventionally be understood as the past in the narration, they would be traveling back in time. Or you can look at the mini-sequence that consists of panels 5 and 6 , in which the bather with the striped bathing suit is initially in front of the protagonist Walt (panel 5) and thereafter (panel 6) she bumps into him while being at the same time behind him.

The paths of reading multiply thanks to the intentionality (not univocality) of the narration. To get a basic understanding of the story the sequences 1-5-9, $1-5-8-9,1-5-8-9-10$ or $1-4-7-10$ are more than enough. Within the general 
narrative, some panels are strongly interdependent, but their correlation is not necessarily univocal. Look at the mini-sequence formed by panels $2-3$, in which Walt first stumbles and then is on the ground. Who threw the ball that you see in panel 3 and that hits Walt's head in panel 4? How does Walt find himself first to the right of the beach - we can see the sea in the upper left corner - and then to the left, chased by a balloon evidently capable of convoluted trajectories? It seems obvious that the logic of sequential reading, but also that which can be derived from the continuity of movement ${ }^{13}$ of bodies and objects, plays a secondary - but co-operative - role with respect to the narrative that can be deduced from the whole.

The charm of the other work by King lies in the fact that, without the aid of the verbal text - which here in a much more preponderant way than in the previous case has the function of directing the direction of reading - it offers, as seeing still precedes reading, a remarkable (but finite) quantity of reading possibilities, within the whole of the page which, as in the previous case, represents a single static background. In sum, the two pages of King taken together can be considered as two maps (hence the act of looking) in which the fragmentation in panels engages an explicit narrative, however multi-vector (the reading). Yet the two levels both cooperate in the story.

It could be objected that, in the cases cited above and especially regarding the second, until the sequential reading intervenes, in the two meanings proposed here, it is not possible to have a true understanding of the narrated story. This is not true or, at least, it is partially true. The confusion generated by the act of observing the first work of King gives the impression of a joyous and carefree day of beach vacation, while the architectural construction of the second sundays, with its abundance of diagonals, contributes to the sense of slight oppression due to an escape that may seem to be hopeless, precisely because the lattice of the comics book cage and that of the house under construction cooperate to create this impression. A direction - which points towards an ending or a finality - exists, both from the graphic point of view and from the sequential/verbal one, but it is certainly not the only way to use these works and perhaps not even the main one. Watching builds the emotional environment in which reading occurs. So we have a context, a map, and a line of time that the words organize as a straight line, while the act of seeing breaks down into different, more ambiguous and articulated forms. These two chronotopes, to use Bakhtin's words, are different and cooperate both by directing the narration on parallel and mirror tracks and generating meaning through the opposition of different and non-coinciding paths.

Roberto Bartual (2019, p. 22) juxtaposes the narration of Frank King to that of Marcel Proust by comparing the Sundays of King a À la recherche du temps perdu:

It is the experience of memory as a simultaneous perception of time what Marcel Proust tried to achieve in À la recherché du temps perdu, but he had to deal with one important fact: we can remember many things at the same time, but

\footnotetext{
13 Term stolen from the language of film scripts and editing and which serves to avoid ambiguity or absurdity in the representation of movement within the frame and between one shot and another. Example: if an actor comes out of a door on the right side of the scene, in the next frame he will not be able to enter from the right, because the lines of the two movements would come into conflict.
} 
we can't read two paragraphs of a book at the same time. ${ }^{14}$ Comics, a medium generally ignorant of modernism, is ironically the only medium with the privilege of representing memory the way Proust wanted, since we are able to see two images at the same time. This Gasoline Alley Sunday page is a proof of it. But there are many others...

And all this happens within one of the grids with the most regular division we can imagine.

The comparison that here is being built between comics, maps and chronologies works best when the reader is not in front of strips or comics or pages that use a strongly cinematographic setting (panel after panel, frequent alternation of fields, to be clear), while it fits perfectly with those authors who prefer a full page composition like Sergio Toppi or Gianni De Luca.

\section{DRAWING TIME ${ }^{15}$}

Figure 3 - Two pages from the Chronicles or Calendars of Eusebius, University of St. Andrews, Scotland

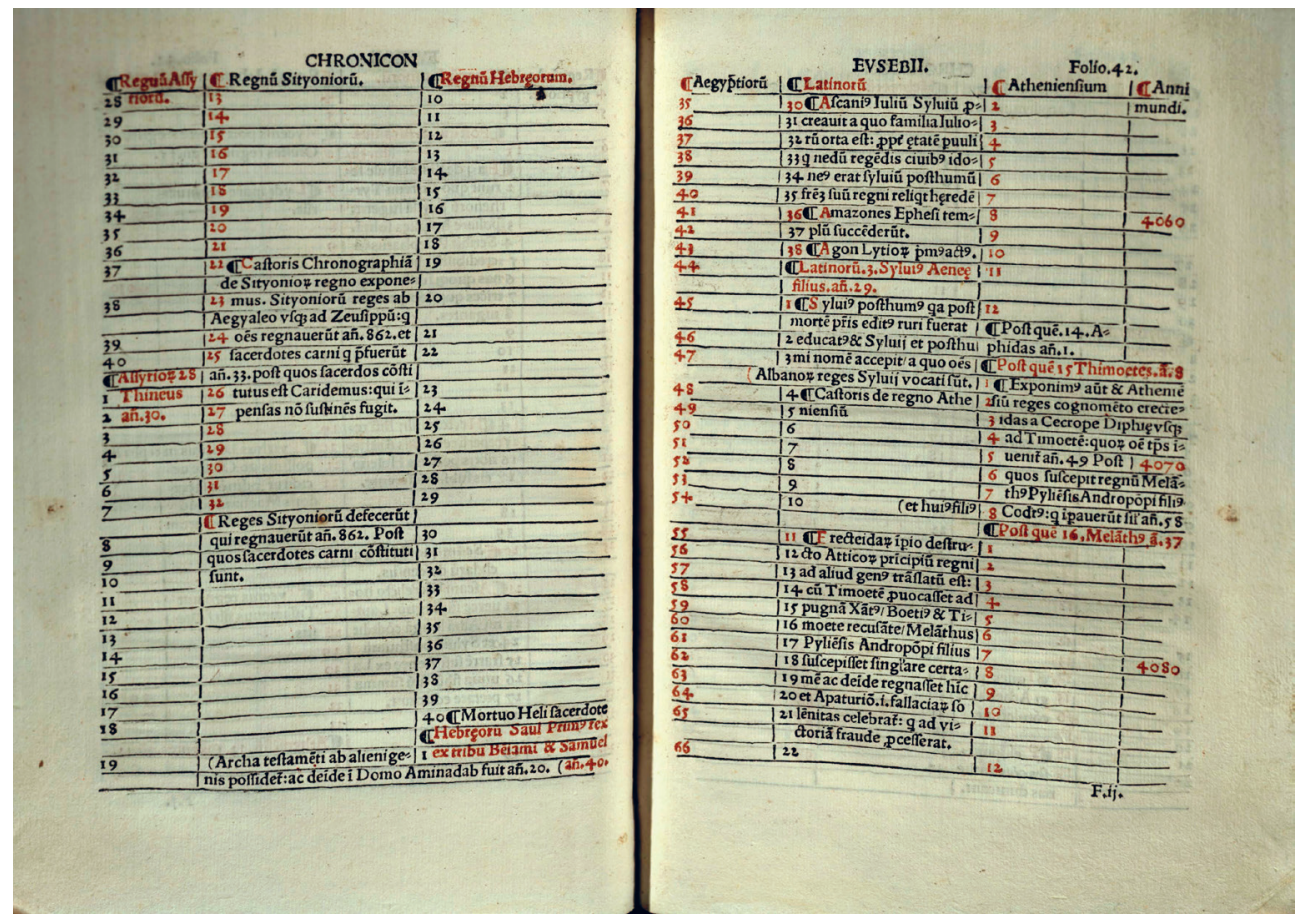

14 Neurosciences tells us that this is not strictly true. Vision is actually a complex and incredibly specialized phenomenon in which single neurons are activated only in presence of specific patterns (for example lines with a certain angle). This information is then coordinated and recomposed in what we perceive as seeing. So it is not a phenomenon that is neither simultaneous nor immediate.

15 Much information on the history of the cartography of time in this chapter comes from the excellent Cartographies of time (ROSENBERG; GRAFTON, 2010). 
The dominant graphic model for the representation of time in Europe from the forth century until the end of the eighteenth century is Eusebius'. This is a simple column chart, with the names of the kingdoms on the horizontal axis at the top and the years inserted in the columns to the left or right of the page. This type of model had obvious limitations. First of all, it did not favor the representation of contemporary and coinciding events, depicting history as a long sequential sequence of moments - kingdoms that succeeded kingdoms - an impression favored by the book form: a line of the story to be leafed through. Beyond that, it was impossible to distinguish the importance of one event from another.

Works such as Fasciculus temporum (1474), by Werner Rolevinck and, above all, the Nuremberg Chronicle (1493), by Hartmann Schedel, break into this linear and regular world made of words and dates arranged in rows and columns, exploiting different types of visual metaphors to represent the passage of time and the concatenation of events. For example, in the work of Schedel a central importance will have, on the model of the Jesse Tree ${ }^{16}$, the theme of the genealogical tree. To the ordered sequence of dates, numbers and names, in short, is added a visual representation that makes chronologies more immediately comprehensible - and more fascinating - by inserting an illustrative dimension, often very elaborate. The historical compilation is accompanied by a narration that we could call literary.

Then, during the following century, different chronologies in the form of trees, candlesticks, hands, etc., will be developed, not counting those based on the iconography of the statue of Daniel, dreamed by Nabuconodosor ${ }^{17}$, while from the cartographic side, we can find examples of anthropomorphized and zoomorphized maps.

It is in the eighteenth century, however, that the visual cartographic metaphor gains momentum and that chronologies try to do without the word. In the Atlas Historicus (1718) of the German engraver Johann Georg Hagelgans, made in a large format, 120 by $85 \mathrm{~cm}$ and based on the usual pattern of lines and columns, graphic suggestions, cartographic inserts, visual representations of the events narrated, can be found alongside the Eusebian chronological model mixing visual history and dramaturgy in a suggestive and effective way.

It is not a comics, of course, but looking in detail at the magnificent work in question, it is impossible, on the other hand, not to find a degree of assonance. Images grafted in a grid and arranged along a time axis and which, depending on the case, are forced inside the casing, which is the result of intersecting lines and columns, while other times they escape, expanding their radius of action along a longer chronological arc. We do not want to say that this is comics, but this type of research on the representation of time will contribute to the birth of the comics, or at least with the comics that will share a similar environment, as it will happen for cinema and for other types of innovations, always related to the representation of time, in the field of figurative arts.

When, in the seventeenth century, the visual cartographic metaphor breaks into chronological representations, the idea that history, in its temporal dimension, can be understood with a single glance and without the aid of words begins to take hold. 
The simple Eusebian scheme gives way, at least visually, to complex maps that illustrate the life of the empires and their correlations on large sheets that go beyond the book form: this is how we can witness the flourishing and spreading of chronologies in the form of a geographical map, of tree, of river. Yet this type of metaphorical temporal representation will soon show its limits and the predominant model in this field will once again be that of Eusebius. The line chosen to represent time, in short, in most cases continues to be a straight line. The real turning point will come only in the eighteenth century and will be radical.

Figure 4 - Joseph Priestley, Chart of Biography, 1765

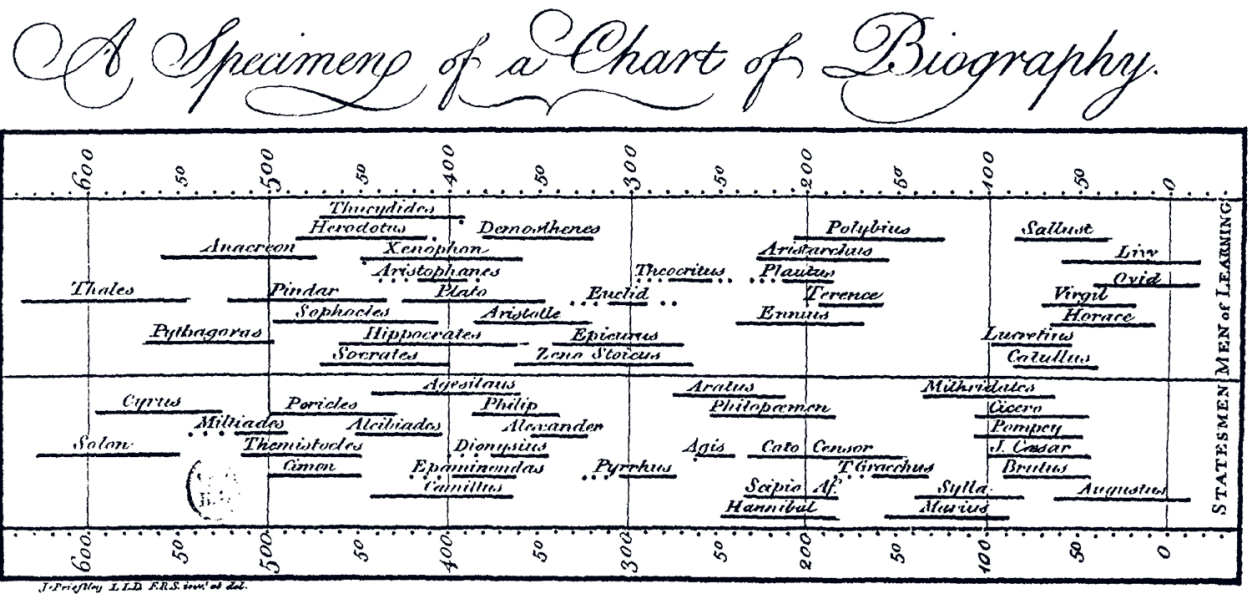

Source: http://courses.ischool.berkeley.edu/i218/s15/Rosenberg.Data.draft.pdf.

A description of a chart of Biography (1765) by the English chemist and philosopher Joseph Priestley represents a decisive step along the path of a purely visual representation of the timeline. The Chart of Priestley covers a period of time ranging from $1200 \mathrm{BC}$ to $1800 \mathrm{AD}$ and represents the lives of two thousand characters, including statesmen, warriors, doctors, mathematicians, artists, poets and speakers. Here is how the author describes his own work:

It is plain that if a sheet of paper be divided into any equal spaces, to denote centuries, or other intervals, it will be a chart truly representing a certain portion of universal time; and if the time of any particular person's birth and death be known, it is but joining the two points of the chart which correspond to them, and you have a line truly representing the situation of that life, and every part of it, in universal time, and the proportion it bears to the whole period which the chart comprises [...] They are the lines [...] which suggest the ideas; and this they do immediately, without the intervention of words: and what words would do but very imperfectly, and in a long time, this method effects in the completest manner possible, and almost at a single glance (PRIESTLEY, 1785, p. 9).

Here we find one of the characteristics of the transmission of information through images, compared with that made through words: the relationship of 
the particular with the whole, immediately (or almost) perceptible both as a general context that includes the detail and as a relationship between the particular and the general.

The linear representation of time as well as being accepted almost immediately, quickly leading to the neglect of other forms of chronological representation from the eighteenth century becomes a mimetic form that implies our perception and our organization of time, a graphic concept that becomes a mental form.

After all, the line is the simplest and most economic form of representation and metaphorization, just as the grid, evident or implied, is the simplest form of organization of the visual material of the comics strip and, at least since the beginning of the twentieth century, the most widespread one, to the point of becoming hegemonic and, at the same time, one of the characteristics automatically and universally associated with the idea that one has of this medium. Line (line) and grid (regular) therefore seem to imply a linear view of the representation of time. We will see that, in the second case, it is not so.

Figure 5 - Syndicat des Auteurs de Bande Dessinée (SNAC BD) manifesto announcing the procession of the authors on the occasion of the 2015 edition of the Angoulême festival

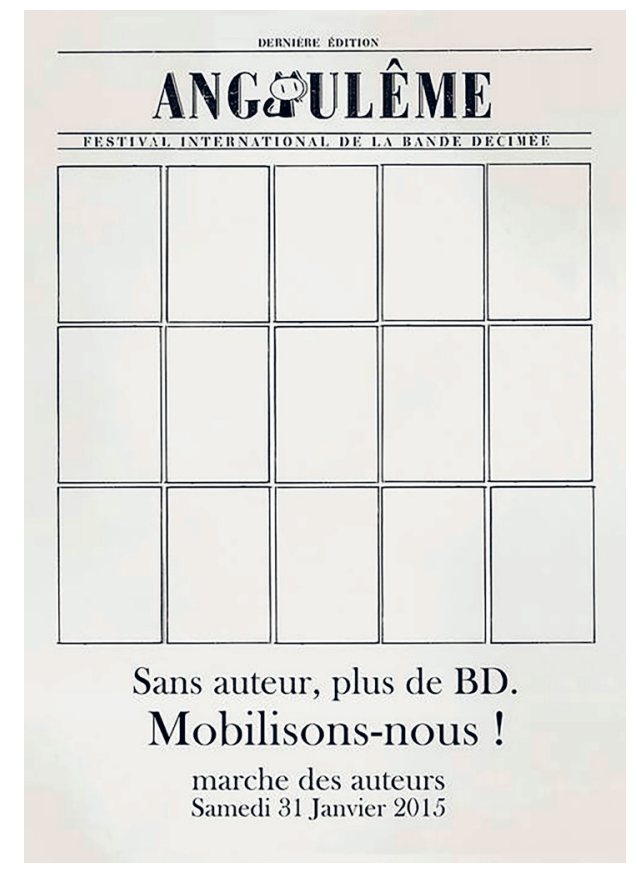

\section{About the grid and the line, about the organization of time}

Today, as readers, we are used to associating the concept of grid with that of comics in an almost automatic way. In reality, the grid becomes the form of organization of comics narrative that we are accustomed to interfacing with today 
only between the end of the nineteenth and the beginning of the TwENTIETH century and, above all, when the comics book is imposed as the main editorial format for the most popular comics in the West.

In an interesting article, Peter Wilkins (2014) defends the grid from preconceptions that liken it to a suffocating and dehumanizing structure, carrying forward the idea that a schematization in which all the elements (be they houses or comics) are closely interconnected may be the most suitable vehicle to combat an individualistic vision of the city and, consequently, that of a sectarian, complicated and sectarian comic. Wilkins (2014) writes:

According to Knight, (KNIGHT, 2013) the grid allows for flow, where suburban cul de sacs are just a bunch of dead ends that block movement. The urban grid's appearance of boredom belies its actual liveliness. What applies to the city also applies to the comic in most instances, particularly Knight's idea that "Good urbanism does not need a plan that looks exciting from the air; it needs a plan that works on the ground". This principle is true for the regular 4 to $12 \mathrm{pa}$ nel grids of comics. While deviations from the regular structure work if they make meaning or control transit for a particular purpose, attempts to make the page layout more exciting for its own sake lead to confusion and irrationality in the structure of the comic, becoming the visual equivalent of a cul-de-sac.

The parallel between comics and urbanism holds up to a certain point, and not only because we should be able to tell whether, as in the case of the representation of time by means of linear graphs, is our perception that organizes information in a grid or, in reverse, is the use of the grid that has influenced the way we organize information, just as it happens with the sequencing of alphabetic writing. The comparison works only in some cases precisely because, if on one hand the - presupposed - greater livability of an urban project based on the structure of the grid has a practical purpose that concerns our daily life, on the other hand there is no apparent reason why an artistic/narrative message should be organized according to the same imperatives, i.e. those of simplicity and regularity. To borrow from Wilkins' ideas, comics must be exciting even if "seen from above", especially if by excitement we mean a component of the comics that precedes that of the sequential reading and that anticipates it and contains it. Naturally, the level of excitement transmitted by the comic strip is not only related to the use of complex and irregular grids, as the already mentioned case of Gasoline Alley has already shown.

Moreover, the grid can serve both to create ambiguity, for example by parcelling the field of vision - see in this regard the initial page of the City of Glass by Paul Karasik and David Mazzucchelli (AUSTER; KARASIK; MAZZUCCHELLI, 2005) - and to direct the use of information through specific channels and through a linear reading, thus preventing the proliferation of meaning. The grid, in addition to being an architecture that allows you to scan the graphical narration through time intervals, regular or not, is a structure that allows you to create the narrative time, not only to stop or dilate it, but to give the idea of its passage even when there is no correspondence between the time of the narration and the time of the story. Think of a comic page, built on a regular modulation of all the same vignettes, in which each of these vignettes represents, from the point of view of the narrative, the same moment, but taken from different points of view. 


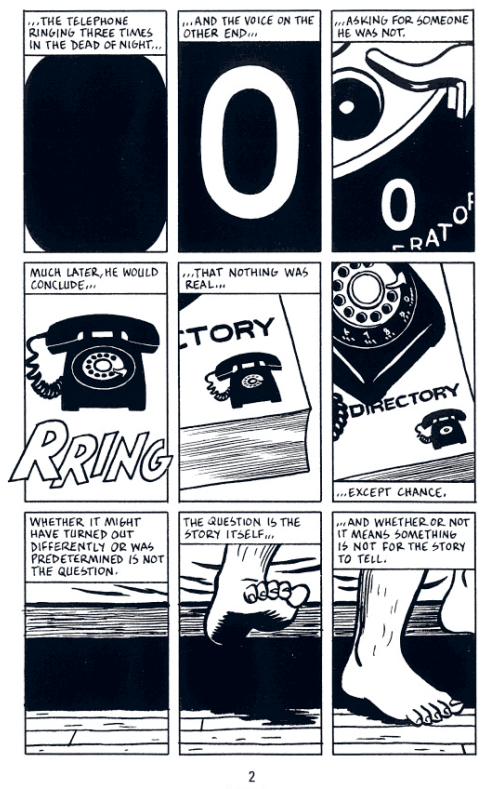

Source: Auster, Karasik and Mazzucchelli (1994).

The grid, in short, beyond the common sense, is a structure with an enormous potential and full of ambiguity. It is not only the structure that defines the sequential narration that takes place in the relationship between the vignettes, but it is the architecture that gives meaning to this narrative. Also based on the grid model are many of the chronologies and biographies brought up to date as examples of the evolution of the forms of representation of time. In these cases, the grid, which is formed by the intersection of rows and columns, facilitates the identification or, better, the immediate display of some information, only by joining, as Priestley says, two points of the diagram. This is possible in types of schematization of this kind, which carries forward a linear idea of time that, without going into the maze of quantum physics, is not naturally the only possible one.

\section{CONTEMPORANEITY AND INSTABILITY}

While in the novel we can not tell events that happen simultaneously, due to the purely sequential nature of writing, the comic book opens up to this possibility. The comic is not (only) a sequential transcription in images of writing, but it often goes to cover those territories where writing is inadequate. As Bartual (2019, p. 22) states in the quote quoted earlier "we can not read two paragraphs of a book at the same time" while we can, in the comic book, "read" - or look at contemporary actions ${ }^{18}$. 
Let's go back once again to the comparison with maps and, above all, with chronological maps. Take, for example, a particular type of chronological map, the family tree. If we were to describe family relationships between individuals, we should use long descriptions to indicate the relationship between two subjects who are on very distant branches of the diagram. While looking at the tree, evaluating the distance that separates them and judging approximately the joints, I can immediately - at a glance - have an impression of their more or less close degree of kinship. The same happens in the case of the chronological maps brought before as an example. This "at-a-glance" view is very distant from a sequential reading process, even if in a second moment this may become necessary, especially if in the chronological map or in the comic strip there is the coexistence of verbal text. Charles Hatfield (2005, p. 48), in the footsteps of Pierre Fresnault-Dereulle (1976), very effectively describes this fruitful ambiguity - "sequence versus Surface" - typical of this language:

In most cases, the succesive images in a comic are laid out contiguosly on a larger surface or surfaces (that is, a page or pages). Each surface organizes the images into a constellation of discrete units or "panels". A single image within such a cluster typically functions in two ways at once: as a "moment" in a imagined sequence of events, and as a graphic element in an atemporal design. Some comics creators consciously play with this design aspect, commonly called page layout, while others remain more conscious of the individual image-as moment. Most long-form comics mantain a tug-of-war between these different functions, encouraging a near-simoultaneous apprehension of the single image as both moment-in sequence and design element. The "page" (or planche, as French scholars have it, a term denoting the total design unit rather than the physical page on which it is printed) functions both as sequence and nonlinear, holistic fashion.

It is no coincidence that the visual metaphor of the river, or of the rivers, is often exploited for the maps of the time ${ }^{19}$. The maps, and more specifically the chronographs, carry the simultaneous presence of the represented elements without excluding the possibility of reading these co-present elements according to their development along one or more axes. The comic moves in space / time in the transition from vignette to vignette (whether this is the time of the narration, the narrative or the reader is secondary) but it is flattened temporally, if one can say so, across the whole page, which in turn can behave like a macrovignette in the economy of its relationship with the other pages of the comics.

One of the comics in which this fruitful ambivalence of reading comics is analysed with more originality - or, rather, the presence of reading and watching - and in which the cartographic metaphor of the river is exploited is Les trois chemins ${ }^{20}$, by Sergio Garcia (penciler) and Lewis Trondheim (writer) (2000).

19 And also for many comics.

20 There are also comics that make it even more explicit the similarity with the simplification or mapping of the map. In this regard, see the work $A-Z$ (ARRHENIUS, 2002) which incorporates the graphic layout of the London underground map to create a hybrid between comics and cartography. Or The Great War (SACCO, 2013), a folding book which can be browsed page by page but which, after being completely opened, goes to form a continuous seven-meter long drawing that reconstructs, at the same time as a narration that as a unitary framework the battle of the Somme. 


\section{LES TROIS CHEMINS, A CHRONOTOPOGRAPHY}

Figure 7 - One double page from Les Trois Chemins

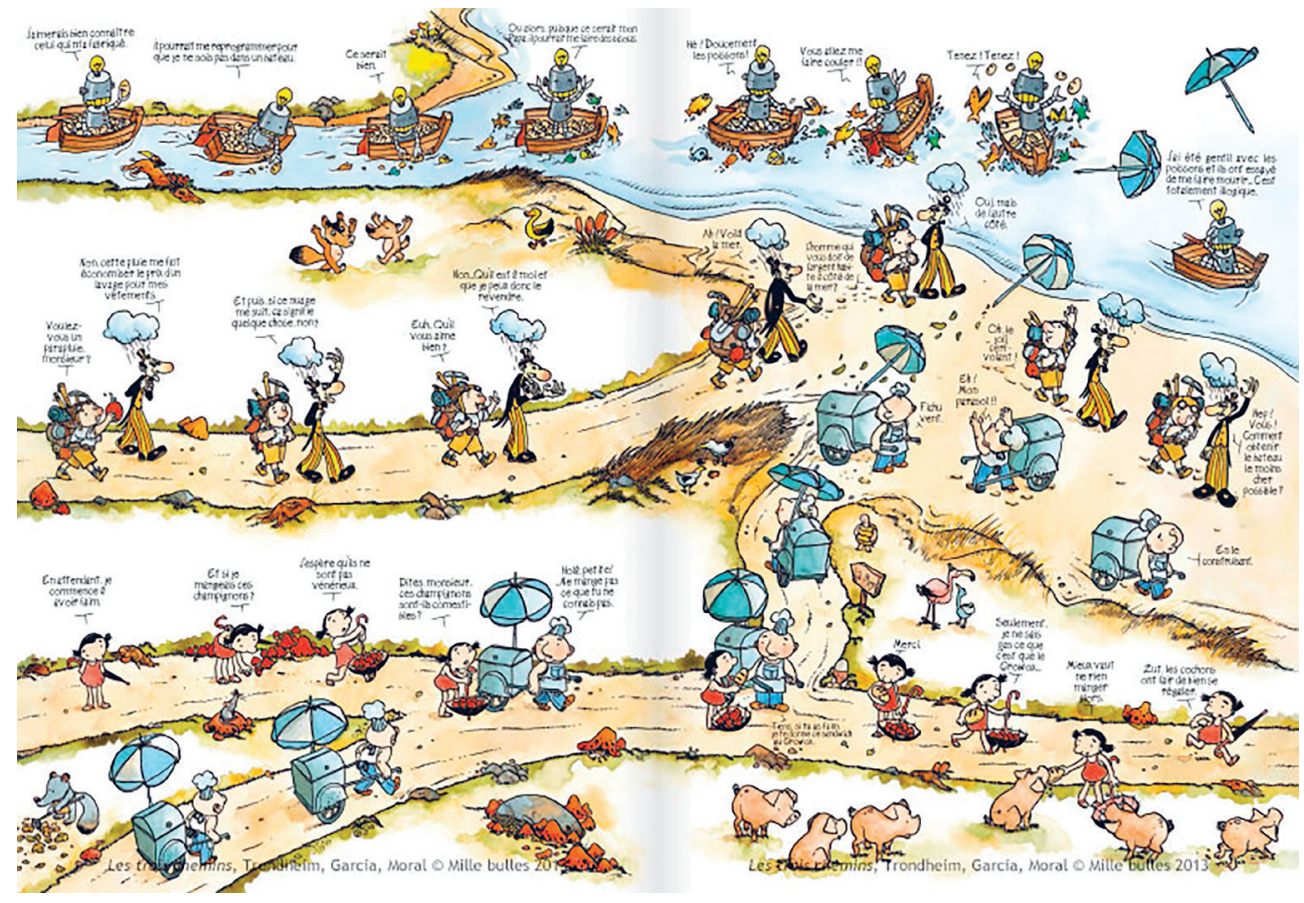

Source: Trondheim and Garcia (2000).

The volume under analysis consists exclusively of full double pages. The first of these double pages, which like the others, does not present any explicit division into vignettes, is built on three parallel horizontal orders. In the upper one, we witness the beginning of the journey of the rich John Mc Mac and his secretary, Robert. In the central order we can see how the day of the ill-fated Roselita begins, a little girl in a red dress. At the bottom, finally, on a boat that drifts along a river is the robot $\mathrm{H}$. Deuzio - nobody knows how he ended up there. The three lines develop, at least at the beginning, both temporally and spatially in the classical sense of Western alphabetic reading, that is, from left to right. As already mentioned, there is no clear separation in panels, but the repeated position of the characters moving along the three different roads replaces the division. What we immediately notice is the coexistence, both on the temporal and geographical level, of the different situations concerning the three narrative lines. Indeed, when the three characters (or groups, if we consider the couple formed by the first two) are on the same vertical axis, they also share the same temporal instant both in the page and in the geography of the comic strip, even though they are in different places.

Already from this first page an internal sequence makes the mechanism explicit. When Roselita enters the old wise man's house, at the same time in the upper strip Robert points down and talks referring to the same house. From the next double pages things get complicated and the streets - understood in the 
physical, topographical, but also narrative terms - intertwine and divide several times, carrying on the story. Here is something that the verbal writing and the novel can not do, if not resorting to syntactic constructions and tangled narratives difficult to manage, while the coexistence of various temporal plans results natural, both in this comic book that represents an extreme case, but also in others perceptively more literary.

The territories of contemporaneity - along a general time axis, however, in evolution - and of the spatial coexistence seem to be of natural relevance to the comic strip. A coexistence that is, in part, also dependent on the way in which the reader approaches the reading of a given comic book.

Of course, simplifying through ideal boundary cases, we can say that there are more literary comics, in which the juxtaposition between vignettes and their consequent sequential reading predominates, and comics in which the general structure of the page imposes itself on the sequentiality of the story vignette after vignette. But it is also true that most of the times these two types of organization of the story coexist and that it is for the reader - in some cases - to prefer one path, one strategy rather than another. It is a question of choosing, when the work permits, between an "on one hand" and "from the whole to the parts" approach. A choice that only the comic, among the narrative media, allows you to do, at least with a certain degree of ease.

Les trois chemins, like the map of Hagelgans, offers a coherent and cohesive backdrop, within the limits of page-by-page reading, on which the characters move and the comparison becomes even stronger if we consider that, beyond the book form adopted to commercialize it, this comic book seems conceived and realized to be able to be unfolded along a single sheet, or a roll, something that does not fade but unfolds, at least before its layout in the volume form. A reflection by Thierry Groensteen is useful and particularly relevant to the case proposed here. The author writes:

At the level of breakdown, if it is only necessary to section an action that is to be represented, a discourse to come, the succession of panels are presented theoretically as a simple end-to-end formation, a strictly linear series. The mental form under which the body is thought of in the work in progress will be that of the ribbon - or the roll of film. For a period of time in which the materiality of the medium is non confronted, the projected work will liken itself to the horizontal thread of successive panels, unwinding the thread of a narration in images (GROENSTEEN, 2007).

Les trois chemins seems to want to recover the lost continuity offered by the ghost of the roll form, or from the imaginary ribbon quoted by Groensteen, but the volume form still imposes its heading. The dislocation of the characters in different positions along the left-right axis breaks with the continuous fluidity of the background, parcelling the time in single moments, those that Hatfield calls "image-as-moment" and that, in fact, makes the narration possible. But at the same time in this work, as in others, we are witnessing the search for the representation of a "cohesive" time, so Barbieri (2008) effectively defines it, that is, the utopia of a representation not subjected to the reduction in single autonomous moments, which will be present across the entire history of comics and find, through the wonderful mediation of the simultaneously and in the escape - by 
DOSSIE

the way impossible - from the cage and the white space, its most original and proper solutions.

Figure 8 - First and last page from How Thing Works Out


Source: Moore and Veitch (1999).

One of the most complete examples of these chronotopographical comics is the short story How Things Work Out, episode of the series Greyshirt published in Issue n. 2 of Tomorrow Stories in November of $1999^{21}$. The page layout is adapted to the diagram of the section of an apartment building. The pages are horizontally divided into four vignettes, corresponding to the four floors of the building. In the upper panel, corresponding to the third floor, it is described what happens in 1999; in the one below (second floor) the events related to 1979; in the next (first floor), the action is set in 1959 and, in the last (ground floor), we find ourselves following a story that takes place in 1939. The spatial continuity, differently from what happens in Les Trois chemins, does not reflect a temporal continuity but, rather, the division in vignettes allows to follow events that are dramaturgically connected to each other - also thanks to the presence of the same characters described in different years - but chronologically distant. At the same time, however, reading paths multiply. In fact, in every page, the point of view changes. In the first page, we can see what happens outside the building; in the second one we see the events set in the apartments of the same building (and, in the case of the lower vignette, in the atrium) and so on. 
Figure 9 - Crazy Quilt, The Chicago Sunday Tribune, May 3, 1914



There are also many pages dating back to the glorious period of the Sunday Pages that can be taken as further examples. One of the most surprising and complex is the Sunday series Crazy Quilt, published in the Chicago Sunday Tribune from April 12 $2^{\text {th }}$ to June $7^{\text {th }}$, 1914. The pages of Crazy Quilt (the English term refers to the traditional patchwork typical of North America, composed of parts of fabric of different shapes, materials and colors, recalled in the background in which the title is framed) are presented as a mixture of different comic series, some already appeared on the pages of the magazine, others created for the occasion. The effect is, even for the modern reader, rather unsettling. Not only the sequence of the stripes is forced to co-exist with the simultaneity of the various situations described in the individual series, but also this operation forces the reader's eye to follow paths that are more varied (linear, circular, fragmented, intersecting, etc.), involving him also from the motoric point of view, when he will be forced to rotate the page to better appreciate the plot. We see that even here, in the pages proposed as an example, the visual metaphor of the road or river takes more or less same value that it has in Les trois chemins.

In conclusion, without wanting to force the comparison with the maps of time to its extreme limits, it must be said that, by introducing the narrative and kinetic elements, the comic behaves more like a diagram, parallelism that deserves a separate reflection. Painting, and consequently the illustration, are not comic even when they present a sequence of images. This is because pictorial representation presents a series of usually topical moments ${ }^{22}$. while comics, like diagrams - a

22 For example, the "gestural culminations" mentioned by Carmela Lombardi (1991, p. 166), that is, "the minimum segment of the movement of the body that represented the semiotically and aesthetically relevant trait of the kinetic sequence". 
family to which the maps of time belong or may belong because a diagram is a cartogram that does not depend on the representation of a territory or a portion of space - stage a transformation in progress. Moreover, a transformation that, influenced by external forces, not only provides a progression, but also articulations that make it possible to represent the presence of more eventualities or alternative narrative universes, which are not excluded but coexist, at least in the form of possibilities. And this not through a succession of topical moments but very often, in the comic strip as in the diagram, through a succession of intermediate moments (the panels, the geometric shapes of a flowchart) that, due to their unstable and passing nature, allow the progression of the narration, unable to fossilize in the infinite moment of classical painting.

\section{Comics AND MUTATION}

Gain Langran (1992, p. 28) explains what the real purpose of cartography is:

It is useful and interesting to examine the thoughts of philosophers concerning the nature of time and reality. But the goal of cartography is neither to discover nor to represent all of reality [...] Rather, the goal of cartography is to distill from "reality" its most important elements and represent them in a manner suited to their application. For this reason, cartographers can sidestep debates on what time is, and instead focus on how best to represent its effects.

The comic and, more in general, the systems of narrative representation that are based on a grid allow to stage a coexistence of frozen moments (but also consequential between them) that is strongly opposed to a perception of time both unidirectional and linear. Skipping the considerations of Langran (1992, p. 37-38) on the representation of time through a three-dimensional construction (a "space-time cube"), in which two dimensions represent space and the third, in fact, time, which still offer some possible and interesting applications for comics ${ }^{23}$, let's concentrate on the definition of "Sequent Snapshots":

A second common model of spatiotemporality is snapshot of time slices. The nature of each time slice is captured by Wood and Fels (1986), who describe maps as sequent snapshots that record only fixed phenomena because moving phenomena become transparent blurs on the film. [...] we can consider that such a snapshot would capture all phenomena whose granularity of change aproximates its exposure time. Time-slice snapshots are an intuitively appealing space-time model. They have roots in traditional mapping and mimic the progressive nature of a slow-motion video. They are in current use to approximate spatiotemporality in a GIS [Geographic Information System]. However, snapshots are a crude means of representing the most important component of cartographic time: change. Each snapshot describes what exists at T. But to detect how $T_{i}$ differs from $T_{j}$, the two snapshots must be compared exhaustively. The root of the problem is that snapshots represent states but do not represent the events that change one state to the next (LANGRAN, 1992, p. 38-39).

The parallel, hopefully evident, between time slice and comics panel must stop here, because while in the first case the event to be represented is chosen depen-

23 See, just to give some examples, the works of the Japanese Shintaro Kago and the French Fred (Frédéric Othon Théodore Aristidès). 
ding on how significant it is at a given moment - that is, to reconnect with what has been said for painting, the "culminating moment" of a process is often represented - in the comic book the choice of what to represent in the vignettes depends on different variables concerning the advancement of the plot and the different dramatic and aesthetic visions that characterize every single work. However, the problematic highlighted by Langran regarding the impossibility of representing change also involves the medium here in question. This medium, in fact, is able to represent sequences of moments and states, but not, if not through different levels of approximation, the intermediate changes that lead from one state to another. Yet, the ability to suggest the mutation, if not precisely to place it at the center of its rhetoric, is one of the most important aspects of comics, at least according to some theorists, such as Benoît Peeters (1991) and Henry Van Lier (1988).

In the meantime, look at a comic book that is very well known and enormously important for the influence it has had and continues to have on the medium for example on the work of the American cartoonist Chris Ware - as it has radically challenged the concept of comics as sequential art: Here, by Richard McGuire, originally published in the journal Raw, v. 2, n. 1, in 1989. The six pages of Here are structured in a cage with six vignettes (2x3) which in turn contain other vignettes, or inserts, for a total of 85 . The six vignettes of the main cage show a fragment of space, an initially unadorned room corner, recounted in a time span from the year 500.957.406.073 BC to year 2033 AD. The narration is not chronologically ordered and the vignettes that open inside the $2 \times 3$ cage function like time gashes that show portions of the future or of the past in the same spatial context, marking a contemporaneity of events that fights both against a linear and progressive vision of time, and against the idea of comics as a sequential art. As you may have understood, to explain in words the structure of Here is not only very difficult, but it completely frustrates the particular perceptive and narrative experience offered by this work.

Figure 10 - First page from Here

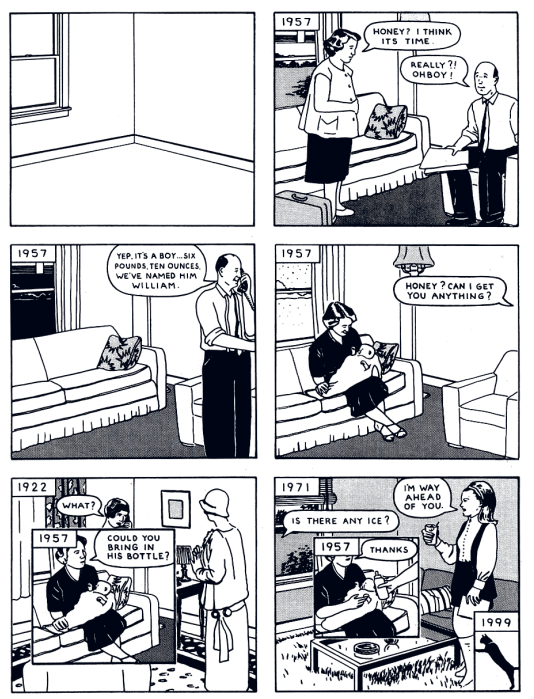

Source: McGuire (1989). 
In Here, in which, unlike the cited example of Les Trois chemins, space (or rather, the point of view of the observer/reader) is still, while it is time that moves, these "temporal inserts" work exactly like the time-slice defined by Langran, even if their purpose is anything, but merely informative.

Here overcomes the idea of comics as a sequential art - and consequently, also, any feared proximity to writing - because it puts on paper, through a choice of contemporary representation of events distant in time, but not disconnected, something that, in the wake of what has been from Bartual, is more akin to the functioning of memory, even if in the specific case it is an abstract and inhuman or post-human memory: the memory of simultaneity. And, more importantly, Here seems to offer, like and more than other examples reported here, one even partial solution to the problem raised Langran, on the impossibility of the representability of the mutation.

\section{ORIGENS HETERODOXAS DE HISTÓRIA EM QUADRINHOS: CALIGRAMAS, CRONOLOGIAS E MAPAS}

Resumo: A história dos antecedentes das histórias em quadrinhos muitas vezes focalizou nas expressões (pintura, caricatura, literatura etc.) que apresentavam semelhanças evidentes com o meio em questão. Há territórios que permanecem pouco ou totalmente inexplorados e que podem não apenas ter contribuído para dar aos quadrinhos a forma que conhecemos hoje, mas ainda podem contribuir para a sua constante modernização e lançá-lo para o desafio da multimídia. Os antecedentes heterodoxos escolhidos aqui são os caligramas, mapas e cronologias.

Palavras-chave: História em quadrinhos. Caligramas. Mapas.

\section{REFERENCES}

ARRHENIUS, L. AZ. London: Peer, 2002.

AUSTER, P.; KARASIK, P.; MAZZUCCHELLI, D. City of Glass, New York: Avon Books, 1994.

AUSTER, P.; KARASIK, P.; MAZZUCCHELLI, D. Città di vetro. New York: Avon Books, 1994.

BARBIERI, D. Il tempo coeso di Gianni De Luca. In: HAMELIN (ed.). Gianni De Luca. Il disegno pensiero. Bologna: Black Velvet, 2008.

BARTUAL, R. Gasoline Alley, 22 April 1934. Available at: http://blog.comicsgrid.com/blog/king-frank-gasoline-alley-april-22nd-1934/. Accessed on: Apr. 11, 2019.

CAPRONI, A. M. I pensieri dentro le parole. Scritti di teoria della Bibliografi \& altre cose. Manziana (RM): Vecchiarelli, 2008.

CARROLL, L. The hunting of the snark. London: Macmillan, 1876.

CASTELLI, A. Eccoci ancora qui 1895-1919. I primi 25 anni del fumetto americano per quotidiani. Milano; Lucca: IF; Museo Nazionale del Fumetto, 2006. 
COHN, N. Navigating comics: an empirical and theoretical approach to strategies of reading comic page layouts. Frontiers in Psychology, n. 4, 2013. Available at: Ncbi.nlm.nih.gov/pmc/articles/PMC3629985. Accessed on: Apr. 15, 2019.

FLOCH, J.-M. Une lecture de Tintin au Tibet, Paris: PUF, 1997.

FRESNAULT-DEREUlLE, P. Du linéaire au tabulaire. Communications, Paris, n. 24, p. 7-23, 1976.

GARCIA, S.; TRONDHEIM, L. Les trois chemins. Paris: Delcourt jeunesse, 2000. GROENSTEEN, T. The system of comics. Jackson: University Press of Mississippi, 2007.

GUGlielmi, G. Mallarmé, Marinetti, Apollinaire. Un'estetica tipografica. In: PARMIGGIANI, C. (ed.). Alfabeto in Sogno. Dal carme figurato alla poesia concreta. Milano: Mazzotta, 2002.

HAGELGANS, J. G. Atlas Historicus. Frankfurt, 1997. Available at: https:// www.raremaps.com/gallery/detail/33235gm/atlas-historicus-illustrated-eusebian-historical-table-hagelgans. Accessed on: Nov. 11, 2018.

HATFIELD, C. Alternative comics. An emergin literature. Jackson: University Press of Mississippi, 2005.

HORROCKS, D. Inventing comics: Scott McCloud's Definition of Comics. The Comics Journal, Seattle, n. 234, June 2001. Available at: http:/ /www.hicksville. co.nz/Inventing\%20Comics.htm. Accessed on: Nov. 11, 2018.

HORROCKS, D. The perfect planet. Comics, Games and World-Building, Hicksville, n.d. Available at: Hicksville.co.nz/PerfectPlanet.htm. Accessed on: Apr. 17, 2019.

IGAKI, T. et al. Eye catchers in comics: Controlling eye movements in reading pictorial and textual media. In: INTERNATIONAL CONGRESS OF PSYCHOLOGY, 28., 2004, Beijing. Available at: http://www.mi-as.com/wp-content/uploads / 2007/05/2004ohmori.pdf. Accessed on: Nov. 11, 2018.

LANGRAN, G. Time in geographic information systems. London: Taylor and Francis, 1992.

LOMBARDI, C. La dipintura poetica. Problemi di costruzione del racconto nei testi di teoria e critica della letteratura e di altre arti del primo Settecento. Chieti: Solfanelli, 1991.

McGUIRE, R. Here. Raw, v. 2, n. 1, 1989.

MOORE, A. B. Maps as Comics, Comics as Maps. 2009. Available at: https:// icaci.org/files/documents /ICC_proceedings/ICC2009/html/refer/24_2.pdf. Accessed on: Apr. 15, 2019.

MOORE, A.; VEITCH, R. Tomorrow stories, Wildstorm, n. 2, Nov. 1999.

MOORE, A. B. et al. Comic strip narratives in time geography. International Journal of Geo-Information, v. 7, n. 7, p. 245, 2018. Available at: https://www. mdpi.com/2220-9964/7/7/245. Accessed on: Apr. 15, 2019.

NICHOLLS, P. Modernisms. A literary guide. Berkeley: University of California Press, 1995.

NODIER, C. Histoire du roi de Bohême et de ses sept chateaux. Parigi: Delangle fréres, 2001. Available at: https://gallica.bnf.fr/ark:/12148/bpt6k108013v. Accessed on: Apr. 15, 2019. 
ORAZI, V. Avanguardia e scrittura calligrammatica. Per una riflessione teorica con spunti ispanici. In: CANCELLIER, A.; LONDERO, R. Le arti figurative nelle letterature iberiche e iberoamericane. Atti del 19 Convegno, Roma, 16-18 settembre 1999. Padova: Unipress, 2011. v. 1.

PEETERS, B. Case, planche, récit. Comment lire une bande dessinée. Tournaï: Casterman, 1991.

POZZI G. La parola dipinta. Milano: Adelphi, 1996.

PRIESTLEY, J. A description of a chart of biography with a catalogue of all the names inserted in it and the dates annexed to them. London: J. Johnson, 1785. ROLEVINCK, W. Fasciculus temporum. Utrecht, J. Veldener, 1480 (1474) Available at: http://objects.library.uu.nl/reader/index.php?obj=1874-313329\&lan $=$ nl\&_ga $=2.148775413 .392654999 .1555536411-61925556.1555536411 \# \mathrm{pa}$ ge/ / 10/25/86/102586181518577322099723661407250506514.jpg/mode/ 1up. Accessed on: Apr. 15, 2019.

ROSENBERG, D.; GRAFTON, A. Cartographies of time. New York: Princeton Architectural Press, 2010.

SACCO, J. The Great War: July 1, 1916. The first day of the Battle of the Somme. New York: WW Norton \& Company, 2013.

SCHEDEL, H. Nuremberg Chronicle. Nuremberg, 1493. Available at: https:// cudl.lib.cam.ac.uk/view/PR-INC-00000-A-00007-00002-00888/55. Accessed on: Apr. 15, 2019.

TRONDHEIM, L.; GARCIA, S. One double page from Les Trois Chemins. Delcourt, V. 1, 2000.

VAN LIER, H. La bande dessinée: une cosmogénie dure. In: GROENSTEEN, T. (ed.). Bande dessinée, récits et modernité. Parigi: Futuropolis-Cnbdi, 1988. p. 5-24.

WALL-ROMANA, C. Cinepoetry: imaginary cinemas in French poetry. New York: Fordham University, 2013.

WERTHAM, F. Seduction of the innocent. New York: Rinehart, 1954.

WILKINS, P. Life on the Grid: Comics and the Everyday. The grid as the most human of ordering and routing systems. 2014. Available at: http://mediacommons.org/tne/pieces/life-grid-comics-and-everyday. Accessed on: Apr. 15, 2019.

Recebido em 12 de novembro de 2018. Aprovado em 23 de março de 2019. 